Journal of Social Sciences 8 (2): 258-262, 2012

ISSN 1549-3652

(C) 2012 Science Publications

\title{
Quality Business Service Provider in Community Enterprise
}

\author{
Chalard Chantarasombat and Tantawan Singkeaw \\ Research Unit and Development of Community Strength and Knowledge Management, \\ Faculty of Education, Mahasarakham University, Maha Sarakham, 44000, Thailand
}

\begin{abstract}
Problem statement: The development of community enterprises focuses on the development of service providers for commercial industries and community enterprises and it is necessary to create and extend the development according to the changing global conditions. The department of industrial promotion and industry promotion center region 5, Khon Kaen must create and develop the quality of service providers in community enterprises as an exclusive course to find a model and development guideline in effective operations that is efficient and appropriate according to the particular community. Approach: The objectives of this research were: (1) to recruit and select at least 15 individuals to participate in the training of service providers in community enterprise in Kalasin province. (2) To define the structure, content, create a curriculum and development of service providers in community enterprise. (3) To develop the participants basic skills training, create motivation, learning experience through on the job training and business management and capability in the diagnosing the cause of problems. (4) To develop the participants understanding of community product standards and provide advice and consultation on the preparation and application of manufacturing standard certification of community products, community enterprise management and provide advice in the implementation of management standards of community enterprises. (5) Satisfaction of the participants training in service providers in community enterprise. Results: 29 people applied for the training program and 26 passed evaluation which was higher than the target of 15 individuals. The theoretical training courses prior to the training had an overall average of 5.06 and after the training had an average of 15.80, the average progress was 10.74. The exercise training through on the job training was regarded as a vocational skill and hand an average of 5.27 before the training. After the training the average was at 16.20, the average progress was 11.13. The evaluation of the performance of the participants of service providers in community enterprise by comparing the average post- training score was higher than before the training, statistically significant level of 0.05 . The course on vocational training for service providers in community enterprise by comparing the average post- training score was also higher than before the training, statistically significant level of 0.05 . The participants were satisfied with the training of service providers in community enterprise as a whole at the highest level with an average of 4.86 and a standard deviation of 0.32 . The participants were satisfied with the overall professional training skills at the highest level with an average of 4.84 and a standard deviation of 0.42 . Conclusion: The developed model and training results are successful in creating quality service providers in community enterprise and on the job training exercise is highly successful in providing knowledge and experience to the trainees. The performance of service providers in community enterprise by comparing the average post- training and prior to training had a score higher than before training, statistically significant level at 0.01 . The trainees are satisfied at a high level. The impact of the research led to a sustainable network of community enterprises in Kalasin province, structure, continuous working mechanism and location for the operation of a central network.
\end{abstract}

Key words:Construction and development, quality, service provider, community enterprise, participatory action research

Corresponding Author: Chalard Chantarasombat, Research Unit and Development of Community Strength and Knowledge Management, Faculty of Education, Mahasarakham University Maha Sarakham, 44000, Thailand 


\section{INTRODUCTION}

Past policies created to enhance the role in promoting the development of community enterprises in the past focused on the development of service providers for commercial industries and community enterprises. To be consistent with The National Economic and Social Development Plan \#10 (ONESDB, 2006) and provide strategic support necessary to conduct business in a systematic manner and in line with current business conditions of being a service provider, it is necessary to create and extend the development according to the changing conditions (Chantarasombat, 2002). Therefore, The Department of Industrial Promotion and Industry Promotion Center Region 5, Khon Kaen must create and develop the quality of service providers in community enterprises which is a specific course to find a model and development guideline in effective operations that is efficient and appropriate according to the particular community. The research area in Kalasin province was chosen for the pilot study and development of service provider in community enterprise training as an exclusive training program. To support the creation and development of a quality business service in community enterprise and meet the needs of the community enterprise with a high standard of service and for the consultants to have the knowledge to expand their ability to provide services to the community enterprise which requires the creation and development of service providers in community enterprise and the preparation of a strategy to develop the potential of the target group through workshops and on the job training at community enterprise establishment that is appropriate to the development and consistent with the service of the network in the future. It is necessary to create and develop a network of service providers in community enterprise for the development of service providers to meet the quality requirements of clients (Chantarasombat et al., 2010). Therefore, The Research Unit and Development of Community Strength and Knowledge Management, Faculty of Education, Mahasarakham University, The Department of community enterprise services and the industrial promotion center, region 5 , department of Industrial Promotion have cooperated in the development of an operation model that will create and develop a network of service providers in community enterprise in Northeast Thailand. The creation of an appropriate network of learning and cooperation in the operation and performance of the network of community will be extended and enhanced for future development in other regions.

\section{MATERIALS AND METHODS}

Purpose of the research: (1) To recruit and select at least 15 individuals to participate in the training of becoming service providers in community enterprise in Kalasin province. (2) To define the structure, course content, create a curriculum and development of service providers in community enterprise. (3) To develop the participants basic skills training, create motivation, learning experience through on the job training and business management and capability in the diagnosing the cause of problems. (4) To develop the participants understanding of community product standards and provide advice and consultation on the preparation and application of manufacturing standard certification of community products, community enterprise management and provide advice in the implementation of management standards of community enterprises. (5) Satisfaction of the participants training to become service providers in community enterprise.

Research Area and Methodology: The targeted group of the research is recruiting at least 15 prospects of service providers in community enterprise in Kalasin province. The participants must have the following characteristics; (1) is currently a service provider of agencies, organizations, institutions, government, educational institutions, private institutions involved in providing information services and support the operation of community enterprise, SME and have at least 1 years of experience in their position. (2) Is someone who is interested in the profession of providing service in regards to general business management and receives authorization from the administrator of their establishment (3) Must be working in Kalasin province. (4) Methodological research on the project and improve the quality of the service provider in community enterprise in Kalasin province and Research and Development by implementing Participatory Action Research (PAR).

\section{RESULTS}

Model development: Publicize and invite candidates to participate and organize a meeting for participant selection and recruitment targets.

Study the problems and needs of the target group through workgroup discussions on the problems of the operation and performance of community enterprises in Kalasin province so that the group can define the problems, status, obstacles and development needs on developing service providers in community enterprise. 


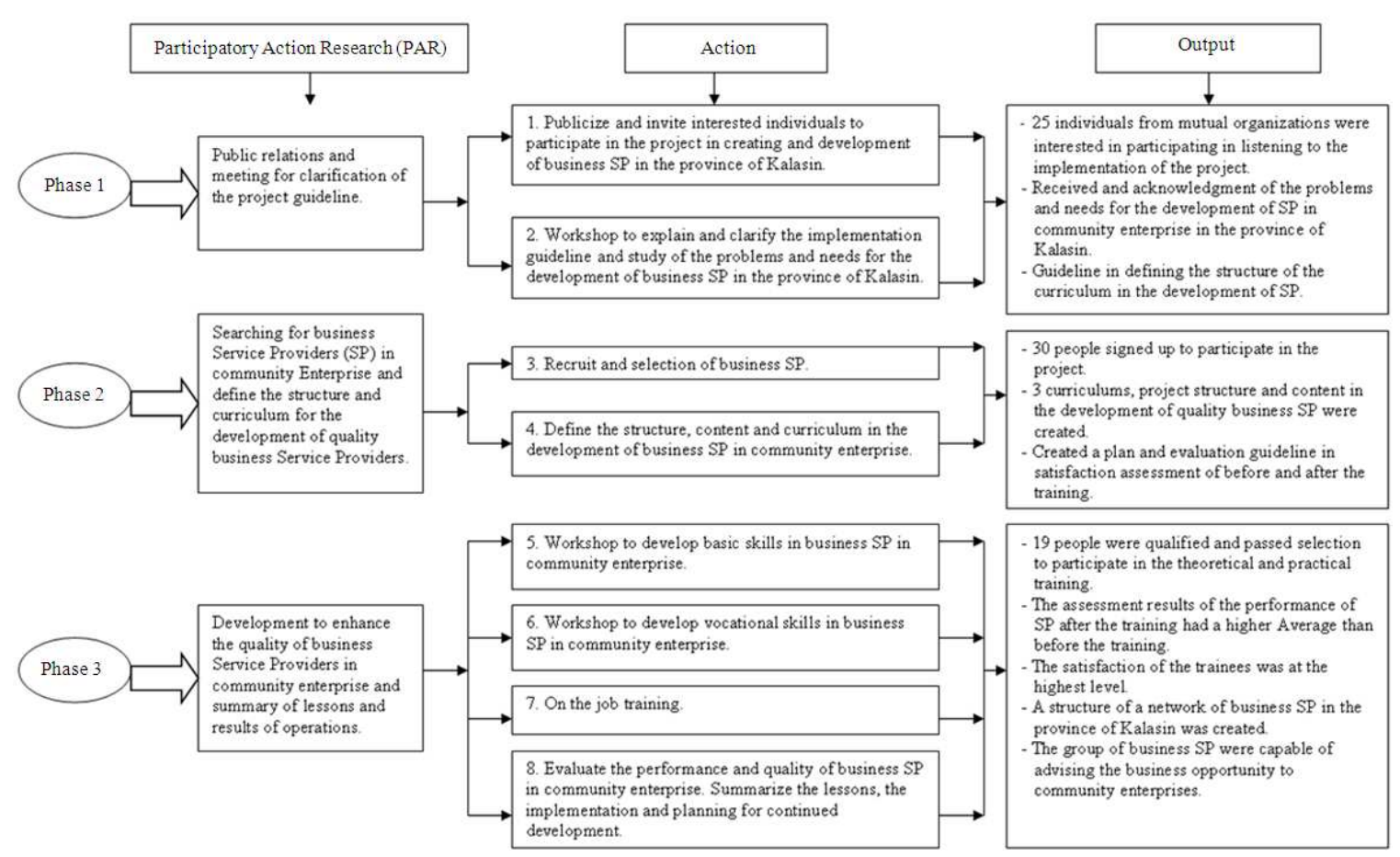

Fig. 1: Model for creating and the development of quality business SP in the province of kalasin

Find and recruit service providers in community enterprise through publicizing and invite interested individuals and perform a selection process and define the structure of the curriculum to develop service providers in community enterprise.

Organize meetings and a team of experts to plan the development of service providers in community enterprise and develop a curriculum to train and develop service providers in community enterprise in the format of a training course base on $30 \mathrm{~h}$ of academics and on the job training exercise at community enterprise establishments in Kalasin province for at least $48 \mathrm{~h}$. The meeting was held on April 25th 2011 at the convention room \#303, Faculty of Education, Mahasarakham University.

The research project was carried out over a period of 6 months from February-August 2011 and included $30 \mathrm{~h}$ of academic classes which were divided into $15 \mathrm{~h}$ of skill development in service provider of community enterprise which were held on May 11-12th, 2011at Rajamangala University of Technology Northeastern University Kalasin and $15 \mathrm{~h}$ of professional development programs in community enterprises at the University of Technology Northeastern University Kalasin on June 1-2, 2011.

Training program and exercise through on the job training at the community enterprise establishment for
48 h. Participants were divided into 3 groups of 8 people and the community enterprise skills in 3 groups which are; (1) Herbal medicine group of Decha Somngam at 83, Tambon Nago, Amphur Kuchinarai, Kalasin province. (2) Don Wai Community Enterprise group at 17 Tambon Dohngling, Amphur Komlasai, Kalasin province and (3) Souvenirs group and Ban Thai Charoen, Moo 8, Tambon Yang Talad, Amphur Yang Talad, Kalasin province.

Organize a meeting to summarize the quality of performance of service providers in community enterprise and the results of the third period which was conducted on July 26th, 2011 at the Polytechnic College, Kalasin. The model for creating and the development of quality business Service Provider in the province of Kalasin is according to Fig. 1.

29 people applied for the training program and 26 passed evaluation which was higher than the target of 15 individuals. The theoretical training courses prior to the training had an overall average of 5.06 and after the training had an average of 15.80 , the average progress was 10.74. The exercise training through on the job training is regarded as a vocational skill and hand an average of 5.27 before the training. After the training the average was at 16.20 , the average progress was 11.13. The evaluation of the performance of the participants of service providers in community enterprise by comparing the average post- training 


\section{J. Social Sci., 8 (2): 258-262, 2012}

score was higher than before the training, statistically significant level of 0.05 . The course on vocational training for service providers in community enterprise by comparing the average post- training score was also higher than before the training, statistically significant level of 0.05 . The participants were satisfied with the training of service providers in community enterprise as a whole at the highest level with an average of 4.86 and a standard deviation of 0.32 . The participants were satisfied with the overall professional training skills at the highest level with an average of 4.84 and a standard deviation of 0.42 . The results are consistent with Chantarasombat (2002) and Phongphit (2005) in which successful results of the training and learning activities trhough community participation and networking led to the creation of a sustainable network of community enterprises in Kalasin province, structure, continuous working mechanism and location for the operation of a central network.

\section{DISCUSSION}

There were 26 participants in becoming service providers in community enterprise at applied to take part in the project which was more than the projected 15. This is because the curriculum of becoming service providers in community enterprise is not often provided by government offices or the private sector. There are only limited courses and programs and is the cause that many individuals were interested in learning and implementing in their work and occupation.

Participants who received training in becoming service providers in community enterprise have an average of development rating significantly higher than before the training. They also received Mean difference by using t-test statistically significant at 0.05 in both basic theory and professional skills. This is because the researcher and research assistants pre-analyzed and synthesize the content of each curriculum by workgroup discussion before implementing the training program. The research team also exchange experiences and knowledge with the participants and presented the training program to community enterprise experts for verification and accuracy of content, structure, appropriateness and possibility in implementation before finalization. The training program was therefore highly appropriate and consistent according to academics related to this training.

The assessment of potential service providers in community enterprise as a result of the performance of both theory and professional skills, only 19 out of 26 people passed the evaluation. This is because the service providers in community enterprise participants had differences in age and maturity. There were 16 participants aged over 45 years and they had problems in reading, writing and difficulty in analysis which affected the impact assessment of the basic theory. Professional skills were not affected and the experience was mandatory and didn't impact the assessment.

The participants were satisfied with the training in service providers in community enterprise and the professional skills and basic theory at the highest level. Because the researcher the and research assistants were experienced in organizing a stage for the exchange of knowledge and social theories, workshops, participatory tree model, the application of comprehensive techniques in quality management and diagrams that focus on action learning. The participants were interested and received continued learning from on the job training. The activities were enjoying from the initial planning development, study of problems, the need, participatory planning, implementation and development, reflection and the exchange of learning. These are the most effective learning methods for the development of community groups (Rammasut, 1997).

The sustainability of the network of service providers in community enterprise in Kalasin was a high possibility which is consistent with Chantarasombat (2004), because the exchange of knowledge the end of the project, created an executive committee of network service providers in community enterprise at a provincial level. Consistent with Tarawneh et al. (2008) in which public participation, involvement of private organizations and the integration of resources will improve the sustainability and success of public services and local development which are driven by the needs of the social network, continuous cooperation and follow-up. Further enhancement and development is possible if Maha Sarakham University, Research Unit and Development of Community Strength and Knowledge Management and the Industrial Promotion Center Region 5 continue their follow-up support and development.

\section{CONCLUSION}

The developed model and training results were successful in creating quality service providers in community enterprise and on the job training exercise was highly successful in providing knowledge and experience to the trainees. The performance of service providers in community enterprise by comparing the average post- training and prior to training had a score higher than before training, statistically significant level at 0.01 . The trainees were satisfied at a high level. The impact of the research led to a sustainable network of community enterprises in Kalasin province, structure, continuous working mechanism and location for the operation of a central network. 


\section{ACKNOWLEDGEMENT}

The researchers would like to thank the Industrial Promotion Center, Region 5, Department of Industrial Promotion for the financial support and funding for the research project.

Suggestions and recommendations: The implementation period should be extended to 1-2 years which will reflect the practice and training of the target group, self development, confidence and follow-up for making improvements.

There should be sufficient funds to maintain and encourage the target group to perform a pilot test which should result in becoming quality service provider in community enterprise.

There should be research and development of a curriculum in service providers in community enterprise in other provinces to find a suitable model of service providers in community enterprise.

There should be research and evaluation of service providers in community enterprise in practical implementations in commercial workplaces and supported into becoming professional service provider in community enterprise.

\section{REFERENCES}

Chantarasombat, C., 2002. Learning process to enhance the strength of community enterprise: Case study of mulberry transformation group at the community of namklieng, tambon naka, amphur wapipatum, maha sarakham province. Maha Sarakham, Research Unit and Development of Community Strength and Knowledge Management, Mahasarakham University.
Chantarasombat, C., 2004. Creating and developing community network for self dependency. Maha Sarakham, Research Unit and Development of Community Strength and Knowledge Management, Mahasarakham University.

Chantarasombat, C., 2010. Creating and developing business service in community enterprise. Maha Sarakham, Research Unit and Development of Community Strength and Knowledge Management, Mahasarakham University.

ONESDB, 2006. The national economic and social development plan \#10 (2007-2011). Prime Minister's Office, Bangkok.

Phongphit, S., 2005. Network: Strategy for a stronger public and stronger community. Chulalongkorn University Book Center, Bangkok.

Rammasut, P., 1997. Participatory action research. P.A. Living, Bangkok.

Tarawneh, Z.S., N.A. Hadadin and A.N. Bdour, 2008. Policies to enhance water sector in Jordan. Am. J. Applied Sci., 5: 698-704. DOI: 10.3844/ajassp.2008.698.704 